\title{
Next-Generation Optical Access Seamless Evolution: Concluding Results of the European FP7 Project OASE
}

\author{
Marco Forzati, Alberto Bianchi, Jiajia Chen, Klaus Grobe, Bart Lannoo, \\ Carmen Mas Machuca, Jean-Charles Point, Björn Skubic, Sofie Verbrugge, \\ Erik Weis, Lena Wosinska, and Dirk Breuer
}

\begin{abstract}
Increasing bandwidth demand drives the need for next-generation optical access (NGOA) networks that can meet future end-user service requirements. This paper gives an overview of NGOA solutions, the enabling optical access network technologies, architecture principles, and related economics and business models. NGOA requirements (including peak and sustainable data rate, reach, cost, node consolidation, and open access) are proposed, and the different solutions are compared against such requirements in different scenarios (in terms of population density and system migration). Unsurprisingly, it is found that different solutions are best suited for different scenarios. The conclusions drawn from such findings allow us to formulate recommendations in terms of technology, strategy, and policy. The paper is based on the main results of the European FP7 OASE Integrated Project that ran between January 1, 2010 and February 28, 2013.
\end{abstract}

Index Terms-Broadband optical access; Fiber optic networks; FTTH; NGOA.

\section{InTRODUCTION AND Motivation}

$\mathbf{E}$ nd-user demand for bandwidth is continuously increasing [1]. As access networks currently constitute a bottleneck in the delivery chain, there is a common understanding that fiber-to-the-home (FTTH) will overcome the bandwidth limitations of today's copper-based and hybrid-fiber access solutions, e.g., fiber-to-the-cabinet (FTTCab). FTTH can be seen as the ultimate future-proof access deployment and the basis for next-generation fixed access.

Considering the high costs associated with operation of access networks, there is a desire that next-generation

Manuscript received June 25, 2014; revised December 2, 2014; accepted December 10, 2014; published January 30, 2015 (Doc. ID 214289).

M. Forzati (e-mail: marco.forzati@acreo.se) is with Acreo Swedish ICT Stockholm, Sweden.

A. Bianchi is with Ericsson Telecomunicazioni SpA, Pisa, Italy.

J. Chen and L. Wosinska are with KTH Royal Institute of Technology, Stockholm, Sweden.

K. Grobe is with ADVA Optical Networking SE, Martinsried, Germany.

B. Lannoo and S. Verbrugge are with iMinds, Ghent, Belgium.

C. Mas Machuca is with TUM, Munich, Germany.

J. C. Point is with JCP Consult, Rennes, France.

B. Skubic is with Ericsson AB, Stockholm, Sweden.

E. Weis and D. Breuer are with Deutsche Telekom AG, Berlin, Germany. http://dx.doi.org/10.1364/JOCN.7.000109 optical access (NGOA) solutions not only cater to the increasing bandwidth requirements, but also enable site consolidation as an avenue for minimizing total cost of ownership (TCO). In addition to new technical solutions, the deployment of new access networks will require large investments and potentially new business models, including using new players like utilities, construction companies, and public administration as key infrastructure investors and drivers, especially in rural areas.

The goal of the Optical Access Seamless Evolution (OASE) project was to identify NGOA solutions that meet the future requirements in terms of, e.g., bandwidth, availability, and scalability at minimum TCO. This paper summarizes the results of the European FP7 OASE Integrated Project (January 1, 2010-February 28, 2013). Different NGOA solutions are proposed and benchmarked against commercially available fiber access solutions, such as gigabit passive optical networks (G-PONs) or active optical networks (AONs).

\section{OASE NGOA DeFINITION AND REQUIREMENTS}

Within the scope of this project, and throughout this paper, we use the word "system" to refer to physical layer issues, and "architecture" to refer to networking layer issues. NGOA coverage at system, architectural, and service levels as defined in OASE is illustrated in Fig. 1. Within the scope of OASE, NGOA system coverage is the domain for investigation of novel optical technologies and solutions. NGOA system coverage comprises the segment from the optical termination (referred to NT1) at the optical network unit (ONU) up to the optical line terminal (OLT), placed at the local exchange or central access node (CAN) depending on the degree of node consolidation. On an architectural level, which is also the basis for the techno-economic comparison, NGOA coverage stretches from the end user's data termination (referred to as NT2) at the customer side to the edge node (hence including the aggregation section of the network).

\section{A. NGOA Requirements}

Identifying the optimal degree of node consolidation, shifting OLTs closer to the core, presents a trade-off 


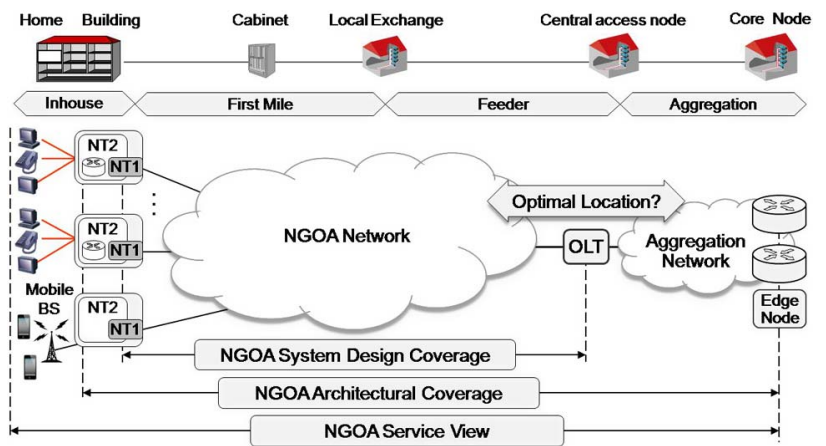

NT1: terminates the optical layer, NT2: control and management plane termination and forwarding

Fig. 1. Overview of the NGOA coverage area as defined within OASE.

between cost reduction associated with node consolidation and the extended NGOA system. Support for larger service areas implies longer access reach and significantly higher customer concentrations per single fiber and single optical interface than in today's G-PON, which has a maximum of 128 customers. It also requires effective redundancy and protection mechanisms. Migration to the NGOA network should not affect already deployed (legacy) systems and spectral usage. Leveraging sunk investments and using existing infrastructure needs to be considered for a costoptimized design and migration strategies. Based on real network topologies and traffic forecasts up to 2030, requirements were identified as baseline for the design and assessment of the NGOA systems and architectures [2,3]. The key requirements are presented in Table I.

\section{B. Network Layers, Market Actors, and Business Models}

Based on the technical and economic nature of the different parts of the network, responsibilities are typically split into three conceptual levels (Fig. 2). On the lowest level, the physical infrastructure provider (PIP) is responsible for rights-of-way, ducts, fibers, and passive equipment such as splitters and racks. The PIP leases this dark fiber infrastructure to the network provider (NP), who in turn installs the necessary active equipment to provide end-to-end connectivity. Finally, service providers (SP) are responsible for the actual delivery of services (which could be very diverse: single versus multiplay packages, streaming versus on-demand services, etc.). The passive infrastructure is typically characterized by high up-front investments with low economies of scale and is often subject to regulation. The network layer is characterized by higher recurring costs and higher economies of scale. The service layer is dominated by marketing, customer relations, and service innovation. Hence, one can envision the PIP role to be taken up by infrastructure players such as real estate companies, municipalities, and utilities. NPs typically own and operate their network equipment. SPs are most successfully taken by either local companies with territory knowledge or large national and international service providers
TABLE I

NGOA ReQUiREments DeFined by OASE

\begin{tabular}{|c|c|}
\hline $\begin{array}{l}\text { Residential peak data } \\
\text { rate (FTTH) }\end{array}$ & $1 \mathrm{~Gb} / \mathrm{s}$ \\
\hline $\begin{array}{l}\text { Business and backhaul } \\
\text { peak date rate }\end{array}$ & $10 \mathrm{~Gb} / \mathrm{s}$ \\
\hline $\begin{array}{l}\text { Average sustainable } \\
\text { downstream in peak hour } \\
\text { per residential client }\end{array}$ & $\begin{array}{l}\text { Moderate case } 300 \mathrm{Mb} / \mathrm{s} \\
\text { Optimistic case } 500 \mathrm{Mb} / \mathrm{s}\end{array}$ \\
\hline $\begin{array}{l}\text { Maximum } \\
\text { asymmetry }\end{array}$ & $\begin{array}{lccc}1: 2 & \text { ratio between } \\
\text { downstream }\end{array}$ \\
\hline \multirow[t]{2}{*}{ Split/Fan-out } & 256 up to 1024 ONUs per feeder fiber \\
\hline & $\begin{array}{l}128 \text { up to } 500 \mathrm{~Gb} / \mathrm{s} \text { aggregate capacity } \\
\text { per feeder fiber }\end{array}$ \\
\hline \multirow[t]{2}{*}{ Reach } & 20-40 km passive reach (working path) \\
\hline & $\begin{array}{l}60-90 \mathrm{~km} \text { extended reach (protection } \\
\text { path), preferably passive }\end{array}$ \\
\hline \multirow[t]{3}{*}{$\begin{array}{l}\text { Migration, } \\
\text { coexistence }\end{array}$} & $\begin{array}{l}\text { Coexistence with existing } \text { ODN } \\
\text { infrastructure (single fiber solution) }\end{array}$ \\
\hline & $\begin{array}{l}\text { Support of seamless migration (i.e., no } \\
\text { user-wise manual switchovers) }\end{array}$ \\
\hline & $\begin{array}{l}\text { Deployed system and the existing } \\
\text { spectrum must not be affected }\end{array}$ \\
\hline Resilience & $\begin{array}{l}\text { Redundancy and protection mechanism } \\
\text { for a service availability of } \geq 99.98 \% \text { for } \\
\text { mass market. } \\
\text { A single failure impacts limited number } \\
\text { of customers (e.g. 1000) }\end{array}$ \\
\hline \multirow[t]{3}{*}{ Open Access (OA) } & $\begin{array}{l}\text { Support of wavelength OA, either } \lambda \text { per } \\
\text { NP/SP, or } \lambda \text { per user }\end{array}$ \\
\hline & $\begin{array}{l}\text { Support of fiber unbundling in the ODN } \\
\text { (e.g., at ODF) }\end{array}$ \\
\hline & Support of bit stream OA at L2 or higher \\
\hline
\end{tabular}

with broad service offers and bundles and brand recognition.

Within OASE, the open-access paradigm was studied in detail. We should note that we make a distinction between open access and unbundling. Unbundling refers to the case in which a single actor is exploiting both a particular layer and the layer on top of that, while still allowing the

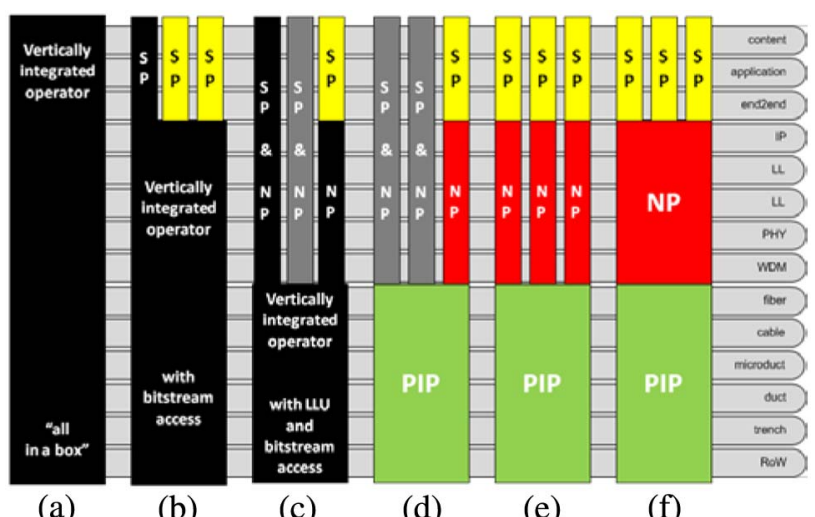

Fig. 2. Conceptual business models for unbundling (a)-(c) and open $\operatorname{access}(\mathrm{d})-(\mathrm{f})$. 
coexistence of other actors on top of its own passive infrastructure/network. Open access, on the other hand, refers to the situation in which the lower layer is provisioned in a nondiscriminatory way to different actors on the layer above. The main difference with unbundling is that the actor responsible for the lower layer is not allowed to act in the layers above. While open access and unbundling do not differ in terms of technical solutions, they tend to lead to different business cases. Figure 2 shows different openaccess and unbundling variants.

Business models for several existing open-access and unbundled FTTH deployments have been studied in detail in Stockholm, Amsterdam, Hamburg, Bavaria, and the rural municipality of Säffle (in Northern Sweden) [4]. The very high infrastructure costs (due to trenching) seem to discourage infrastructure-based competition at the fiber layer. In fact, we typically observe a single PIP per area, e.g., Stokab in Stockholm, M-net in Bavaria, and Glasvezelnet Amsterdam in Amsterdam. On the other hand, the business case for NP-based competition seems more realistic (although the number of NPs is typically limited to a few), and competition at the SP level is common in all examples (SPs can number up to a dozen).

\section{OASE NGOA Solutions}

Different NGOA systems and architectures with the potential of fulfilling the NGOA requirements of Section II, were identified [5] and categorized into four main groups of solutions:

- WDM-PON,

- Hybrid WDM/TDM-PON,

- WDM-PON backhaul,

- NG-AON.

These groups are described in this section. As reference solutions, we consider two widely deployed systems: G-PON and Ethernet point-to-point (which we will refer to as AON P2P in the rest of the paper).

Figure 3 shows the different types of optical distribution networks (ODN) and corresponding NGOA systems in the generic NGOA architecture with consolidated CANs. Note that the same ODN may support multiple solutions and that one solution can be compatible with several ODN types. It should also be noted that despite the name, PON may in some cases contain active elements in the remote node $(\mathrm{RN})$.

\section{A. WDM-PON}

Wavelength division multiplexed PON (WDM-PON) solutions span a set of solutions with dedicated wavelengthdomain multiple access per client. These solutions can be categorized into wavelength-selected (WS-) WDM-PON with power-split ODN and wavelength-routed (WR-) WDM-PON with WDM-filtered ODN. All WDM-PONs can be considered as point-to-point links at the wavelength

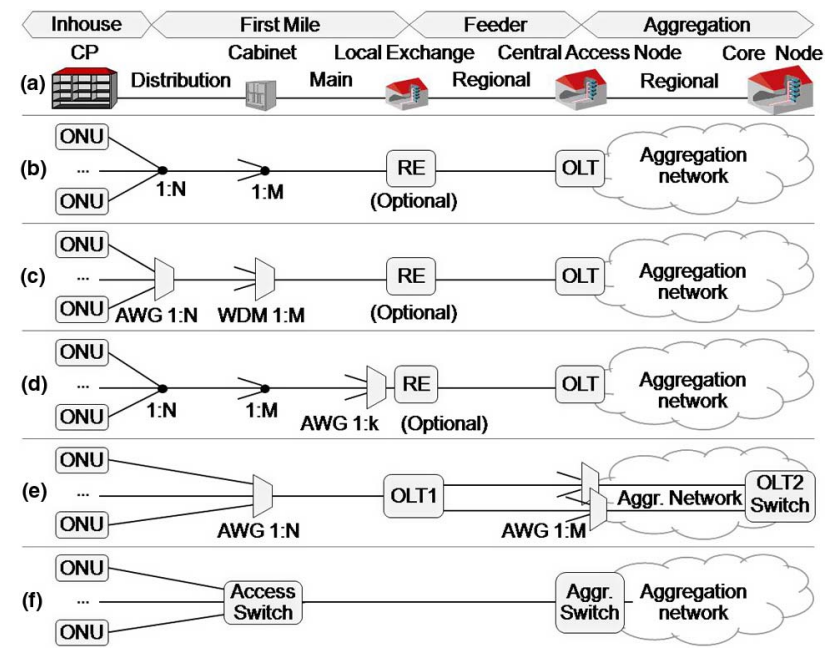

Fig. 3. Typical locations and generic terminology of (a) NGOA architecture and (b-f) NGOA systems solutions. (b) WS-WDMPON, UDWDM-PON, and G-PON/XG-PON1, (c) WR-WDM-PON with WDM-filtered ODN, (d) Hybrid WDM/TDM-PON and (coherent) UDWDM-PON, (e) WDM-PON backhaul, here with WR-WDM-PON in the first mile, and (f) NG-AON, with AON P2P from ONU to the access switch and P2P or WDM backhaul to the aggregation switch. $\mathrm{RE}=$ reach extender.

level and provide a high sustainable bandwidth per customer.

WS-WDM-PON [Fig. 3(b)] is based on passive optical power splitters in the ODN (which limits the reach as compared to WR-WDM-PON). Each ONU is assigned one wavelength pair (downstream plus upstream); therefore the number of ONUs is given by the number of available wavelengths. All wavelengths are available at each of the ONUs. Therefore, tunable receivers (e.g., tunable filters) and a security layer are needed. In addition, tunable lasers or seeded/reflective devices are required for colorless transmitters.

WR-WDM-PON, shown in Fig. 3(c), uses the same OLT as WS-WDM-PON, but uses one or several passive devices in the ODN that can multiplex/demultiplex wavelengths. These are typically arrayed waveguide gratings (AWGs) that route single wavelengths or wavelength pairs to each ONU. The ONUs can be designed either with tunable lasers or seeded reflective transmitters, but do not require tunable receivers.

Ultradense (UD) WDM-PON is a variant of WS-WDMPON where coherent receivers and ultradense channel spacing are used. Consequently, it can run via power-split or hybrid ODN, as shown in Figs. 3(b) and 3(d). It uses coherent detection, which enables dense wavelength spacing, increased reach, and high potential end-user numbers.

\section{B. Hybrid WDM/TDM-PON}

Hybrid WDM/TDM-PON is based on a combination of wavelength- and time-division multiplexing. It can be passive or semi-passive [4]. 
Passive hybrid WDM/TDM-PON [Fig. 3(d)] aims to improve the fan-out of the WDM-PON architecture by using TDM for multiple access. The ODN may be based on different combinations of power splitters and AWGs. A purely power-split ODN has the highest flexibility concerning resource allocation, but suffers from large insertion loss. ODNs containing AWGs can achieve longer reach but with less flexibility. In both cases, ONUs require tunable filters. The upcoming ITU-T Recommendation series G.989 on NG-PON2 describes a hybrid WDM/TDM-PON with up to eight channels and the option of additional point-to-point WDM channels.

In the considered semi-passive hybrid WDM/TDM-PON, the first passive splitting device is replaced by an active reconfigurable optical switch (e.g., a wavelength selective switch, WSS). This active device can switch wavelengths to the different distribution fibers and assign resources in a reconfigurable, less static way while reducing the insertion loss compared to power splitters. For details on system implementations, see [6].

\section{WDM-PON Backhaul}

This is a hybrid AON/PON architecture [see Fig. 3(e)] consisting of two typically PON-based stages (backhaul and first mile) connected by an active element terminating and regenerating the optical signal. The backhaul stage is based on WR-WDM-PON, while the first-mile stage can be based on G-PON, WDM-PON, or even AON P2P. Due to this mid-stage termination, high reach and client count can be achieved at the cost of active equipment in the field.

\section{D. $N G-A O N$}

The next-generation active optical network (NG-AON) architecture is based on active RNs that are placed somewhere in the ODN, for instance, in the cellar of a multidwelling unit or in a cabinet [see Fig. 3(f)]. Each ONU connects to a Layer-2 switch. Higher-layer (i.e., IP) and in principle also lower-layer (i.e., lambda layer) switching is also possible. The backhaul between RN and CAN can be based on different point-to-point technologies, e.g., WDM-PON.

NG-AON can be based on standard star topology (active star or AS-AON), as shown in Fig. 3(f), but if desired, even meshed topologies (in which each node is connected to one, two, or several other nodes) can be relatively easy to implement all the way to the first aggregation point (e.g., the cellar in a multidwelling unit or in a cabinet), assuming this is connected by multiple fiber connections, e.g., connecting neighboring buildings.

\section{Assessment of the OASE Solutions}

The assessment of the four NGOA solutions is presented in this section, together with the reference solutions. First, a system-level assessment is performed, followed by an analysis on the architectural level. Finally, technoeconomic and business-model assessments are performed.

\section{A. System-Level Assessment}

All solutions are assessed with respect to performance and operational parameters with an impact on the TCO: client count per OLT port, floor space requirement (density), energy consumption, provisioning, maintenance, and openaccess compatibility. The assessment results are discussed in some detail in this section and summarized in Table II.

All systems are configured to provide $\geq 1 \mathrm{~Gb} / \mathrm{s}$ peak bit rate and $300 \mathrm{Mb} / \mathrm{s}$ or $500 \mathrm{Mb} / \mathrm{s}$ guaranteed bit rate per client, as defined by the requirements in Section II. For hybrid WDM/TDM-PON and G-PON/XG-PON1, the ODN split ratio is adapted to these bit-rate requirements.

Assessment of reach and client count per OLT port is based on power-budget modeling, while floor space and energy consumption is based on modeling of the respective system configurations. A common power-budget model is used that comprises a total penalty of $5.5 \mathrm{~dB}$ for in-house patching, cabling, measurement couplers, etc. End-of-life fiber attenuation of $0.34 \mathrm{~dB} / \mathrm{km}$ in the C/L-band and $0.44 \mathrm{~dB} / \mathrm{km}$ at $1310 \mathrm{~nm}$ has been assumed. In addition, all systems were configured in order to comply with laser safety class $1 \mathrm{M}$, i.e., a maximum accumulated power not exceeding $21 \mathrm{dBm}$.

In order to investigate floor space and power consumption, a common rack-and-shelf model is used. Each shelf includes mechanics, backplane, redundant power supply, management, and Layer-2 switching, which is adapted to the guaranteed per-client data rate.

The calculations regarding cost, power consumption, form factor, and reach are based on the performances of the key components or subsystems of the respective system configurations. These parameters have been extensively discussed in industry fora like the Full-Service Access Network (FSAN), conferences and workshops, other research projects, and bilaterally with various components vendors. More details on the system-level assessment can be found in $[\underline{5}, \underline{7}-\underline{9}]$.

The component figures for power budgets, power consumption, and cost are subject to uncertainty increasing in this order (i.e., power-budget/IL figures are stable and relative-cost figures have the highest uncertainty). A sensitivity analysis shows that even changes of keycomponents cost by a factor of 2 do not change the overall result significantly.

1) Technical Performance Assessment-Calculations: Because of NG-AON's inherent nature as a nonshared transmission medium, NG-AON solutions can achieve the longest reach $(60 \mathrm{~km}$ from the access switch at the $\mathrm{RN}$ to the end user).

Moving to the more interesting analysis of PON-based solutions, WR-DWDM-PON can achieve a fiber reach of $60 \mathrm{~km}$ with a fully passive ODN for client counts of up to 80 per feeder fiber. A higher client count is possible, 
TABLE II

Cost for the Different NGOA Solutions in Relation to a G-PON ONU

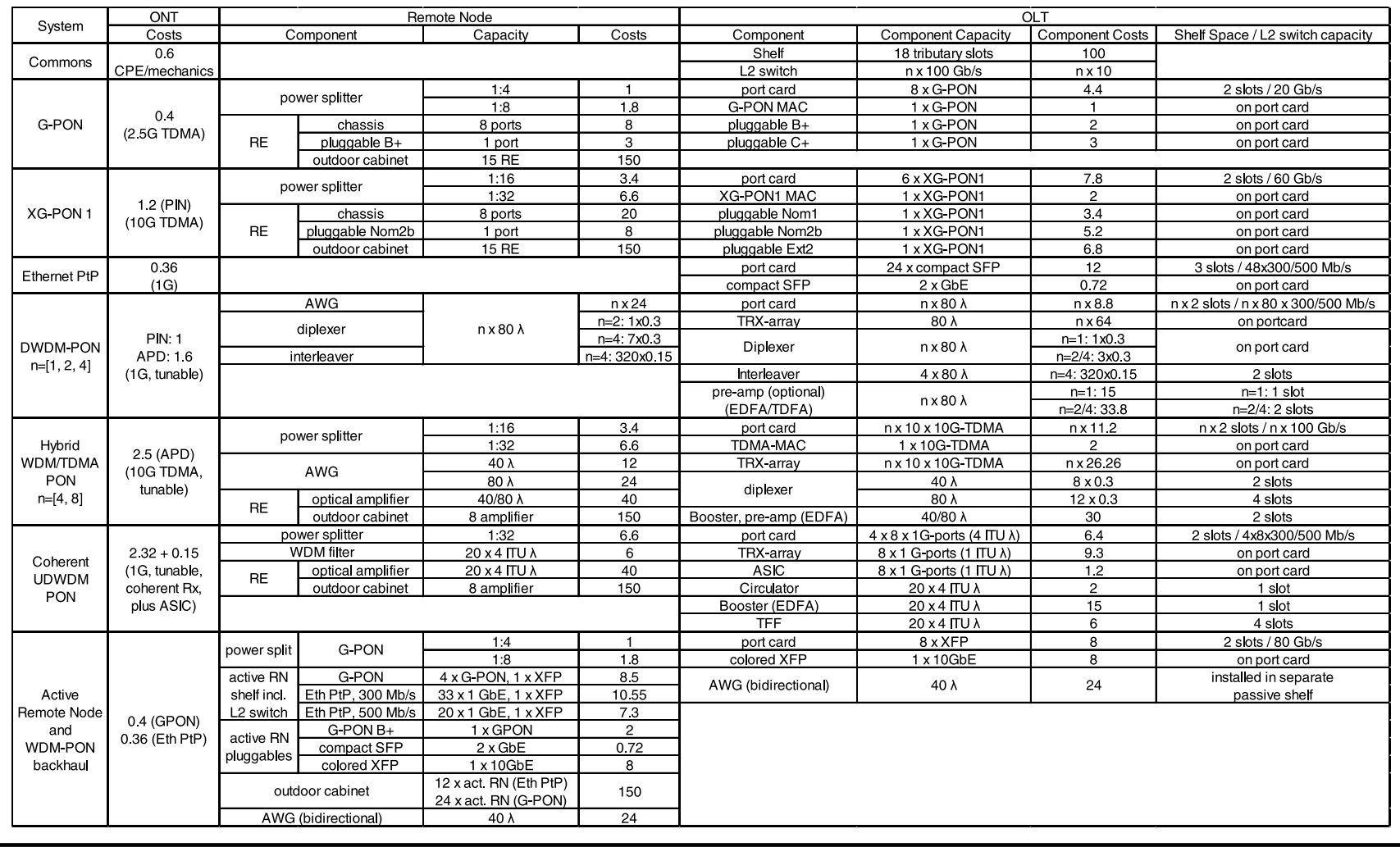

but when it is increased beyond 80, the fiber reach is reduced due to the insertion of additional WDM band splitters or interleavers.

Coherent UDWDM-PON can achieve $\sim 60 \mathrm{~km}$ reach for a client count as high as 320 . The client count can again be higher, but then the reach is likewise decreased.

For hybrid WDM/TDM-PON, the reach is limited to less than $30 \mathrm{~km}$ at a high client count (320 and above), even though booster and preamplifiers, forward-error correction (FEC), and a very high achievable power budget (39 dB) between transmitter and receiver have all been considered.

With WDM-PON backhaul, both long reach $(>40 \mathrm{~km})$ and a large client count (several hundreds) can be achieved. These advantages come at the penalty of needing active RNs. This is addressed by the TCO calculations.

The reach of any of the WDM-based NGOA systems can be increased by active reach extenders, i.e., optical amplifiers. These require local electrical powering, which again has to be considered for the resulting TCO.

The assessment further showed that power consumption is not a major differentiator. Power consumption at the ONU side is somewhat higher for UDWDM-PON and hybrid WDM/TDM-PON due to their complexity, compared to WR-WDM-PON. At the OLT side, power consumption per client is slightly lower for hybrid WDM/TDM-PON due to the sharing of wavelengths among multiple clients. Ethernet PtP has the lowest power consumption per access line. However, network-wide power consumption is increased by the higher number of active sites with aggregation switches.

2) Technical Performance Assessment-Experimental: We also investigated two relevant aspects of NGOA solutions experimentally. These aspects relate to the photonic layer of WDM-based PON. The results are applicable to WDM-PON as well as hybrid WDM/TDM-PON and similar hybrid PONs. The work targeted former weaknesses of WDM-PON: the limits of the achievable bit rate $\times$ reach product for seeded/reflective approaches and the lack of concepts for massive cost reduction in WDM-PON based on tunable lasers.

Increased bit rate $\times$ reach with seeded/reflective transmitters was achieved for the specific variant of wavelength reuse with combined inverse-return-to-zero (IRZ)/returnto-zero (RZ) modulation. Here, the modulated downstream laser wavelength is also used as a seed for a reflective ONU transmitter, which reuses this wavelength for upstream remodulation. In any timeslot, the ONU must receive seed light for upstream transmission. This can be achieved by modulating the downstream with IRZ on/off-keying (OOK) and then using bit-interleaved RZ OOK for the upstream. A block diagram of this system, which was specifically designed to cope with the problems of crosstalk and reflections arising from the use of the same wavelength for upstream and downstream [10], is given in Fig. 4. The reach of the IRZ/RZ WDM-PON was increased to $20 \mathrm{~km}$ at $10 \mathrm{~Gb} / \mathrm{s}$ per channel and $60 \mathrm{~km}$ at $2.5 \mathrm{~Gb} / \mathrm{s}$, respectively [6]. 


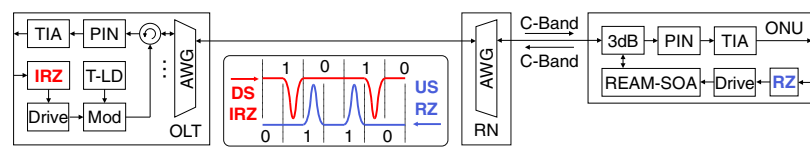

Fig. 4. Ten Gb/s IRZ/RZ WDM-PON. MZM, Mach-Zehnder modulator; T-LD, tunable laser diode; PIN TIA, p-i-n photodiode with transimpedance amplifier.

As an alternative to seeded/reflective transmitters, tunable lasers can be used for colorless ONUs. In order to allow for low cost, the lasers must be fitted neither with their own dedicated wavelength lockers nor with coolers. Hence, they are subject to wavelength drift and require cost-effective wavelength control in the PON system context.

Several control mechanisms were developed and implemented for several different types of wideband tunable lasers (DS-DBR lasers, Y-branch DBR lasers). This included closed-loop control and open-loop control according to a look-up table.

For closed-loop laser control, a distributed wavelength locker was implemented that could be shared between all WDM channels for cost efficiency. The setup is shown in Fig. 5. The upstream lasers in the ONUs were modulated with additional (AM or FM) pilot tones, which were transparent for the payload. These pilot tones were detected in the OLT via a tap, followed by low-speed photodiodes and analog-to-digital conversion. Laser drift could be detected and corrective action be signaled to the ONUs via an embedded control channel (ECC).

Closed-loop control allows wavelength stabilization of the uncooled lasers to within $\pm 5 \mathrm{GHz}$ over a broad temperature range and $\pm 2.2 \mathrm{GHz}$ over $\pm 0.5^{\circ} \mathrm{C}$. This supports wavelength grids down to $25 \mathrm{GHz}$ [11].

3) Assessment of Operational Aspects: The operationalaspects assessment revealed (see [6] for details) that all potential NGOA solutions support the basic operations, administration, and maintenance (OAM) tasks. These consist of fault, configuration, account, performance, and security (FCAPS) management. In particular, automated service provisioning is possible with all solutions given that WDM-based ONUs are colorless and self-installing (which are operators' requirements). This can be achieved, e.g., with tunable lasers which are controlled by the OLT through related signaling channels. Certain advantages regarding fault isolation were identified for NG-AON and WR-WDM-PON due to their capabilities of unambiguously discriminating the individual distribution fibers. This is possibly only to a limited extent for broadcast (power-split) ODN.

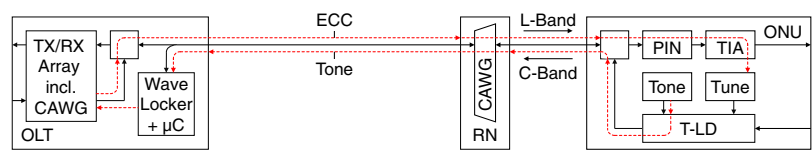

Fig. 5. Closed-wavelength control loop. CAWG, cyclic AWG; Tone: pilot-tone generator; Tune, tuning microcontroller (microC).
Some differences were also identified with regard to the floor-space requirements. Here, hybrid WDM/TDM-PON shows the best density, followed by WDM-PON with integrated multichannel transceiver arrays. In third place for best density is WDM-PON backhaul (due to the requirement for active RNs at the cabinet/local exchange), which is followed by the relatively complex UDWDM-PON. NGAON has the highest floor-space demand, which can clearly be attributed to the high number of active sites.

Regarding open access (OA), no sever differences were found. For all solutions, OA focuses on Layer-2. For WDMbased PONs, OA on the wavelength level is seen as possible, but requires significant additional effort when integrated multichannel transceiver arrays are used.

4) System-Level Assessment Sum-Up: All assessments are based on the basic components-level properties. The systems-level performance assessment did not yet show a clearly winning solution. In general, maximum reach is traded-off by fan-out for all PON solutions, due to the increasing insertion loss. In this regard, $\mathrm{AON}$ solutions have an advantage. Regarding energy consumption, there is no clear picture either. On the positive side, this also means that all solutions do comply with, e.g., the EU Broadband Code of Conduct.

The system-cost comparison shows somewhat higher cost for coherent UDWDM-PON and large variations depending on specific system configurations. For most configurations, cost clearly depends on the guaranteed bit rate. Hence, there are significant differences between the figures for 300 and $500 \mathrm{Mb} / \mathrm{s}$.

The operational assessment did not clarify the ranking. Most solutions perform fairly well with regard to basic operational and open-access requirements. As an example, WR-WDM-PON performs slightly above average.

In order to single out a main system candidate for NGOA, it is necessary to understand which system aspects drive cost with regard to the TCO. This analysis is presented in Subsection IV.C.

\section{B. Architecture-Level Assessment}

Unlike system-level assessment, the evaluation presented in this section maps the selected NGOA options to some specific deployment scenarios, and the results shows the impact of placing (or replacing) equipment in certain locations. In particular, we focus on the impact of node consolidation, providing open access on a wavelength basis, and migration toward the NGOA architectures. Beyond these aspects, evaluation results for power consumption and resiliency can be found in [12-14]. A summary of the overall assessment at the architecture level is provided at the end of this section.

1) Node Consolidation: With respect to node consolidation, it is of crucial importance to understand the long-term effects of moving and concentrating equipment in certain locations for the considered technology options. The consolidation of COs implies that several traditional access 
networks are grouped together to form a new service area, which in turn has a wider coverage, i.e., having more users and longer distances. Two scenarios representing low and high degrees of node consolidation have been investigated. Starting from today's scenario with $7500 \mathrm{COs}$ on a country-wide scale (assuming a country like Germany), we assumed a reduction in the two scenarios (low and high degrees of consolidation) toward 4000 and 1000 nodes, respectively. Here we summarize the results for the urban area for two key operator-related performance metricsfootprint and failure rate-which are also analyzed in the techno-economic study presented in Subsection IV.C. Similar findings were obtained for the other types of service areas (dense urban and rural). A complete assessment on architectural level with respect to node consolidation has been included in [15].

Figure 6 shows the footprint per line required at the various locations in the NGOA architectures, as well as in the reference architectures G-PON/XG-PON in combination with node-consolidation scenarios for the urban service area. Footprint per line is defined as the floor space of all the network equipment that is taken on a per user basis. The methodology for the footprint calculation can be found in [16]. For all the variants of WDM-PON architectures, node consolidation does not make an obvious

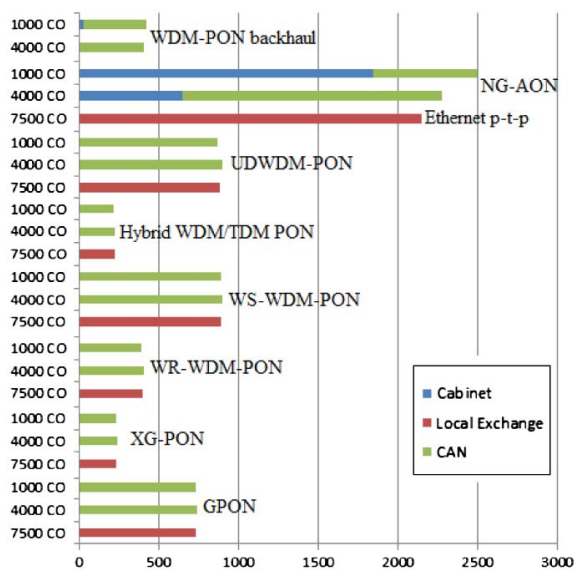

Fig. 6. Footprint per line $\left(\mathrm{mm}^{2}\right)$. impact on the total footprint per line. Hybrid WDM/ TDM-PON requires the lowest amount of footprint in the outside plant among all the evaluated options due to its relatively high sharing factor and fully passive ODN. In WDM-PON backhaul, the footprint of the active $\mathrm{RN}$ equipment at the cabinet/local exchange has also been taken into account. It can be seen that the total footprint for this architecture is slightly higher than for WR-WDMPON. However, in the 1000 CO scenario, equipment space is required at two different locations. It implies that a small portion of traditional COs/cabinets cannot be closed down even in the case of a higher degree of node consolidation. NG-AON requires the highest amount of footprint per line among all the architecture options. In contrast to the passive architectures, the footprint per line in NG-AON is obviously impacted by the degree of node consolidation because of the active equipment needed at a RN (e.g., cabinet) in the field. It also means that the old COs or cabinets cannot be completely closed in the node-consolidation scenarios.

Figure 7 shows the average number of failures per year normalized per line in different NGOA options and G-PON for various node-consolidation scenarios. It can be clearly seen that failures at ONUs dominate in all the evaluated options. In the case of an ONU failure, it is assumed that a new device will be sent to, and installed by, the end user (plug-and-play). Other failures than at the ONU, however, are more costly because they generally require a technician to be sent to the field to perform repair (we can refer to these as critical failures). From Fig. 7, we can see that NG-AON has the highest rate of critical failures (although it has the lowest total failure rate), followed by UDWDM-PON. Hybrid WDM/TDM-PON, on the other hand, has a high total failure rate, but the lowest rate of critical failures.

2) Open-Access Compliance: Based on the different system concepts and architectural investigations, in [17], all of the aforementioned NGOA solutions were analyzed with respect to their potential to enable cooperation between different players as introduced in Section II0, e.g., sharing part or all of the infrastructure and/or equipment. Three methods-namely fiber, wavelength, and bit-stream open access for giving access to a network-have been considered.

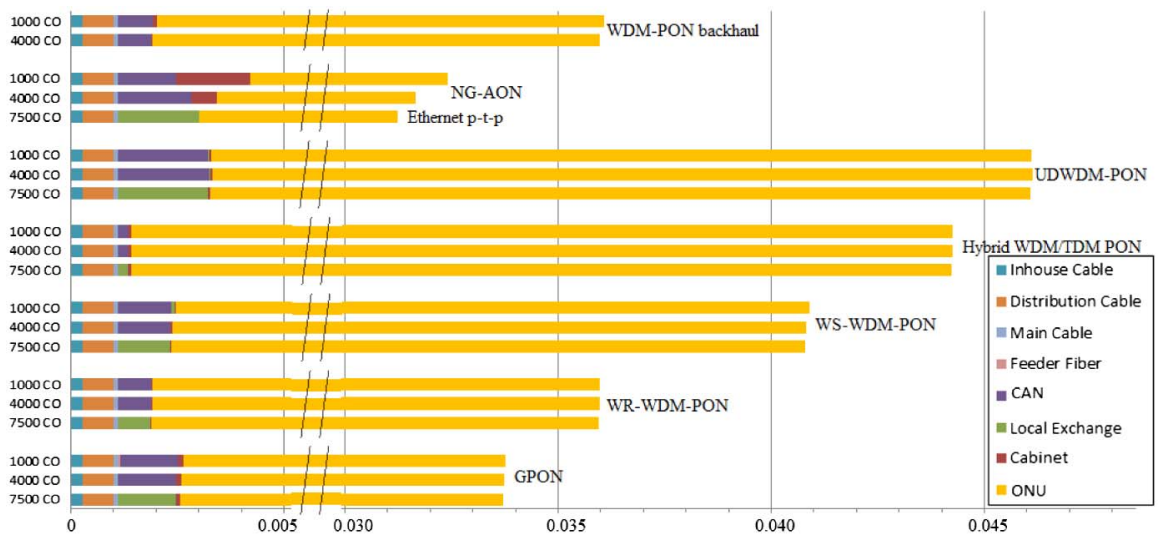

Fig. 7. Number of failures per year normalized per line. 
P2P fiber-level open access is only feasible with AON solutions with a colocation possibility at the $\mathrm{RN}$, or with P2P AON. Bit-stream open access can be adapted to any NGOA architecture option. Both these options are relatively straightforward to implement and widely used today. Here we choose to focus our analysis on wavelength open access.

The main impact of wavelength open access on the PIP comes from the consequent need to manage optical devices (e.g., optical splitters, AWGs, and wavelength selective switches) and manage wavelengths. Wavelength open access can be implemented as 1) wavelength open access at the feeder fiber and 2) wavelength open access at the CAN. The latter option can be implemented by manual reconfiguration of the network each time the customer decides to change NP or by automatic reconfiguration, either in the electronic or optical domain. Optical-domain reconfiguration can be done with

- static spectrum distribution among NPs, using a waveband splitter as an open-access element, or

- dynamic spectrum distribution among NPs, using a power splitter or WSS as an open-access element.

Figures 8-10 illustrate wavelength open access for a WR-WDM-PON. Similar schemes could be applied to the other PON approaches if the isolation issue caused by the power splitter in a power-split ODN could be solved properly, while it is not always possible for active architectures, i.e., WDM backhaul and NG-AON (see [12] for the details and complete assessment of all the OASE NGOA architectures). Figure 8 shows a typical example for the feeder fiber-based WR-WDM-PON open access, where an M:N: AWG is used in the cabinet. Figure 9 shows an example of wavelength open access, using a static waveband splitter as an open-access element at the CAN. Figure 10 shows the general scheme for several variants with dynamic

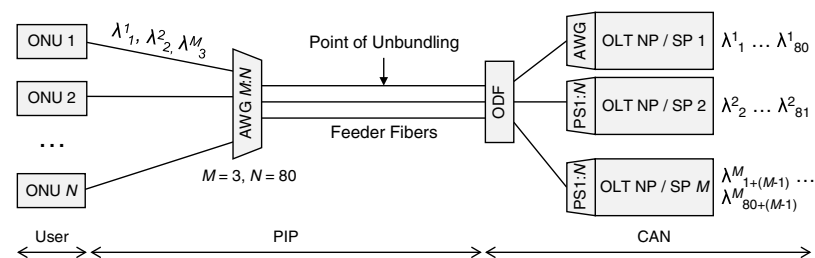

Fig. 8. Feeder-fiber-based wavelength open access in WR-WDMPON.

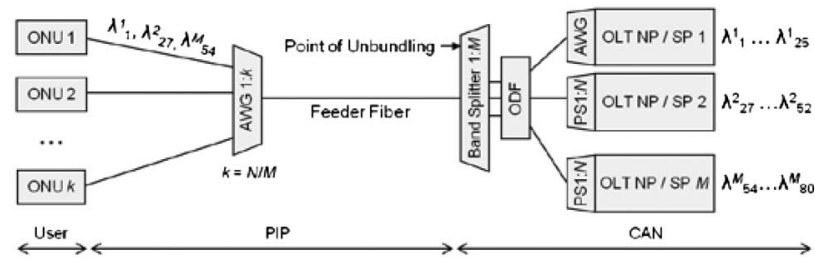

Fig. 9. Wavelength open access at the CAN using a static band splitter in WR-WDM-PON.

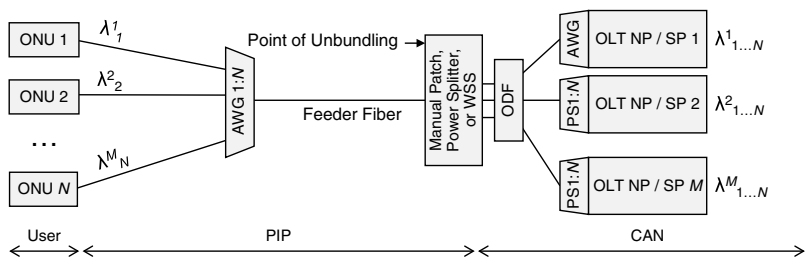

Fig. 10. Wavelength open access at the CAN with dynamic spectrum sharing in WR-WDM-PON.

spectrum sharing between the NPs, either manually [using a patch panel, followed by an AWG to (de)multiplex all wavelengths toward the user] or automatically (using a power splitter or WSS).

It can be noted that additional fibers and/or equipment are needed to enable open access, which further increases the overall cost.

3) Migration: We define two starting points for assessment of migration toward the OASE NGOA architecture options: 1) from a TDM-PON-based ODN (such as used in G-PON/XG-PON) and 2) from a P2P-based ODN (such as used in P2P AON). The assessment is based on the most important migration criteria, categorized according to four migration challenges (i.e., supporting coexistence, reusing legacy infrastructure, minimizing disruption time, and introducing node consolidation). It is clear that using a P2P ODN as a starting point offers the highest flexibility for migration, but in many cases such an ODN is not available. For a power-split ODN, the (passive) hybrid WDM/TDMPON and WS-WDM-PON (and UDWDM-PON) are most suitable from a migration perspective. The other NGOA architectures are less suitable for migration, but offer other opportunities, such as better support for open-access, protection, energy saving techniques, etc. as discussed in the OASE [12-14].

The main conclusions of the migration assessment are as follows:

- Starting from an existing PON deployment, full coexistence is supported by hybrid WDM/TDM-PON, UDWDM-PON, and WS-WDM-PON.

- Full coexistence is not supported by WR-WDM-PON, WDM-PON backhaul, and NG-AON

- System performance (including the number of ONUs per feeder fiber, passive and active reach) depends on the coexistence scenario (i.e., coexistence on the same ODN of NGOA and legacy technologies like G-PON, and/or XGPON whether combined with RF video overlay or not).

- In principle, all NGOA architectures support node consolidation, with a migration of single users on demand.

- In principle, all NGOA technologies can be operated on an ODN with P2P architecture in the first mile, although in deployed multipoint TDM architectures, there might be a shortage of available fibers from the cabinet to the local exchange level for P2P.

4) Summary of the Architecture-Level Assessment: Table III summarizes the key findings of this architectural 
TABLE III

Summary for Architecture Assessment ${ }^{a}$

\begin{tabular}{|c|c|c|c|c|c|c|c|c|}
\hline \multirow{2}{*}{\multicolumn{2}{|c|}{ Architectural aspects }} & \multicolumn{3}{|c|}{ WDM-PON } & \multicolumn{2}{|c|}{$\begin{array}{c}\text { Hybrid } \\
\text { WDM/TDM-PON } \\
\end{array}$} & \multirow{2}{*}{\begin{tabular}{|} 
WDM- \\
PON \\
Backhaul \\
(AON P2P \\
$1^{\text {st }}$ mile) \\
\end{tabular}} & \multirow{2}{*}{$\begin{array}{l}\text { NG- } \\
\text { AON }\end{array}$} \\
\hline & & WS & WR & UD & Passive & $\begin{array}{c}\text { Semi- } \\
\text { passive }\end{array}$ & & \\
\hline \multicolumn{2}{|c|}{ Energy consumption } & - & + & -- & \multicolumn{2}{|c|}{$\mathrm{O}$} & $\mathrm{O}$ & + \\
\hline \multicolumn{2}{|c|}{ Resiliency } & + & + & + & + & $\mathrm{O}$ & $\mathrm{O}$ & $\mathrm{O}$ \\
\hline \multirow{3}{*}{$\begin{array}{l}\text { Operational } \\
\text { complexity }\end{array}$} & $\begin{array}{c}\text { Operator } \\
\text { related energy } \\
\text { consumption }\end{array}$ & - & + & - & \multicolumn{2}{|c|}{++} & + & - \\
\hline & Footprint & $\mathrm{O}$ & + & $\mathrm{O}$ & ++ & & $\mathrm{O}$ & -- \\
\hline & Failure rate & $\mathrm{O}$ & + & - & ++ & & $\mathrm{O}$ & - \\
\hline \multicolumn{2}{|c|}{$\begin{array}{c}\text { Complexity of resource } \\
\text { allocation }\end{array}$} & \multicolumn{3}{|c|}{++} & \multicolumn{2}{|c|}{-} & $\mathrm{O}$ & $\mathrm{O}$ \\
\hline \multicolumn{2}{|c|}{$\begin{array}{c}\text { Open access } \\
\text { (wavelength level) }\end{array}$} & $\mathrm{O}$ & + & $\mathrm{O}$ & \multicolumn{2}{|c|}{$\mathrm{O}$} & - & -- \\
\hline \multicolumn{2}{|c|}{ Migration (from G-PON) } & ++ & + & ++ & ++ & $\mathrm{O}$ & - & -- \\
\hline
\end{tabular}

$a_{++}=$very good; + = good; $\mathrm{O}=$ medium; - = poor; -- = very poor

assessment. Several of the "passive" NGOA architectures, i.e., WS-WDM-PON, UDWDM/WDM-PON, and hybrid WDM/TDM-PON, turn out to consume more energy, but have better reliability performance, than their active counterparts, namely WDM-PON backhaul and NG-AON. From the operators' perspective, i.e., without considering the equipment located at the user side, hybrid WDM/TDMPON, thanks to its high splitting ratio, generally performs well considering operational aspects, such as footprint, failure rate, and operator-related energy consumption. However, for hybrid WDM/TDM-PON, there is an issue with resource allocation for scheduling upstream bandwidth. An efficient algorithm for hybrid PON is needed to mitigate the performance degradation caused by reach extension. Open access on the wavelength level is technically easy to be realized in WR-WDM-PON, e.g., using $M: N$ AWG to replace 1:N AWG (in case multiple feeder fibers are available). However, for all the other types of PONs, the required power splitter in the ODN causes isolation issues for wavelength open access, while it is not even possible for some variants of WDM-PON backhaul and NG-AON. Furthermore, considering migration requirements on coexistence, a fully passive ODN of the type used for WS-WDM-PON, UDWDM-PON, and passive hybrid WDM/TDM-PON is preferable.

A detailed assessment of the OASE architecture options comparing the considered architectural aspects can be found in $[\underline{12}, \underline{15}, \underline{17}]$.

\section{Techno-Economic Assessment}

The NGOA techno-economic assessment targets the evaluation of the capital and operational expenditures (CAPEX and OPEX, respectively) of different NGOA architectures on different areas and node-consolidation scenarios. For that purpose, a frame tool based on TONIC [18] has been developed, as shown in Fig. 11. The techno-economic frame tool is based on the dimensioning of the selected NGOA architecture for a given scenario. The dimensioning considers a geometric model of the user distribution [19]

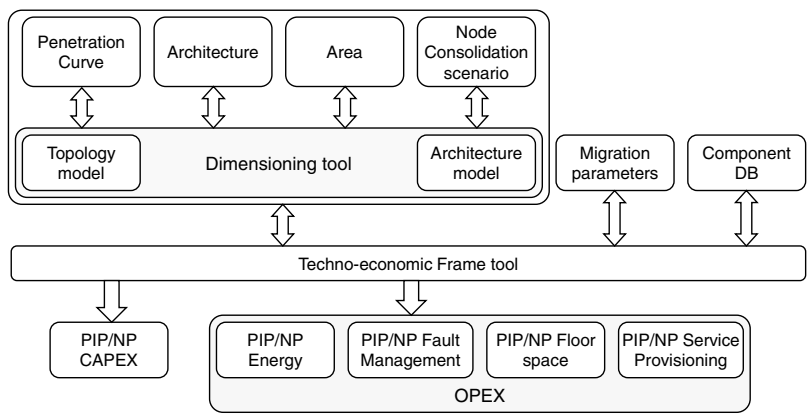

Fig. 11. Techno-economic frame tool.

and, based on the given penetration curve, area, and node-consolidation scenario, it provides a yearly "shopping list" of the equipment and infrastructure required.

Based on the yearly shopping list, and any required information on any network component and possible migration scenario, the cost assessment is performed and delivers yearly distribution of both CAPEX and OPEX. In order to use the cost assessment results in the business model studies, the PIP and NP costs have been differentiated. Any cost of equipment or infrastructure is given as CAPEX, which also includes any associated installation costs. Fault management (FM), energy consumption, service provisioning (SP), and floor space are all considered OPEX. Due to the complexity of FM (complete failure reparation process) and SP (adding, changing, and cancelling customer services) processes, they have been modeled in detail using the business process model and notation (BPMN) and integrated within the extended TONIC tool.

1) Migration Scenarios: Among the several studies performed within the project OASE, this paper presents the cost evaluation of the migration from an existing traditional optical access network such as G-PON or AON. This is the case for many operators. In this migration scenario, the investments in terms of infrastructure and equipment are considered assuming there is an existing ODN, which can be used for migration toward the NGOA. The considered migration scenarios have been summarized in Table IV. The technology migration from G-PON 1:32 or AON P2P to WR-WDM-PON is not studied in the no-nodeconsolidation (NNC) scenario because in this case the new architecture requires considerable ODN upgrade, which is generally not economically feasible.

2) Migration Cost Assessment Without Node Consolidation: The cost evaluation is presented in terms of cost units (CUs), whereby $1 \mathrm{CU}$ equals the cost of one G-PON ONU. Only nondiscounted TCO values are presented. In this way, the real cost is shown as experienced during the given years.

The first cost comparison shows the average from 2020 (migration year) to 2030 of the nondiscounted TCO per user, taking into account the users connected in each year (based on the assumed penetration curve). Figure 12 distinguishes the CAPEX contribution (in blue) from the OPEX contribution (in red) for dense urban (top) and rural (bottom) areas without node consolidation. In the 
TABLE IV

Migration/Upgrade Scenarios Considered in the Cost Assessment and CoRREsponding Node-Consolidation DEGREES $^{a}$

\begin{tabular}{|l|l|l|l|}
\hline \multicolumn{2}{|l|}{ Migration/upgrade scenarios } & NNC & ANC \\
\hline From & To & & \\
\hline G-PON 1:32 & G-PON 1:8 $(>300 \mathrm{Mb} / \mathrm{s})$ & Yes & Yes \\
\hline G-PON1:32 & HPON $40 \lambda 1: 32(>300 \mathrm{Mb} / \mathrm{s})$ & Yes & Yes \\
\hline G-PON1:32 & HPON $80 \lambda 1: 16(>500 \mathrm{Mb} / \mathrm{s})$ & Yes & Yes \\
\hline G-PON1:32 & WS-WDM-PON $64 \lambda(>300 \mathrm{Mb} / \mathrm{s})$ & Yes & Yes \\
\hline G-PON1:32 & WS-WDM-PON 128 $(>300 \mathrm{Mb} / \mathrm{s})$ & Yes & Yes \\
\hline G-PON 1:32 & WR-WDM-PON $80 \lambda(>300 \mathrm{Mb} / \mathrm{s})$ & N/A & Yes \\
\hline G-PON 1:32 & UDWDM-PON $(>300 \mathrm{Mb} / \mathrm{s})$ & Yes & Yes \\
\hline XG-PON1:32 & XG-PON 1:16 $(>500 \mathrm{Mb} / \mathrm{s})$ & Yes & Yes \\
\hline AON P2P & WR-WDM-PON $80 \lambda(>300 \mathrm{Mb} / \mathrm{s})$ & N/A & Yes \\
\hline AON P2P & AON P2P $(>300 \mathrm{Mb} / \mathrm{s})$ & Yes & N/A \\
\hline $\begin{array}{l}\text { AON } \\
\text { ActiveStar }(\text { AS })\end{array}$ & $\begin{array}{l}\text { WDM Backhaul with AON P2P } \\
(>300 M b / s)\end{array}$ & Yes & Yes \\
\hline \hline
\end{tabular}

${ }^{a}$ No-node consolidation (NNC) versus aggressive node consolidation (ANC). The minimum bit rate is $300 \mathrm{Mb} / \mathrm{s}$, although some solutions like XG-PON 1:16 and hybrid WDM/ TDM-PON (HPON) 80 $1: 16$ are able to support higher bit rates $(500 \mathrm{Mb} / \mathrm{s})$.

scenario-realistic for one geographical area-the traditional optical access network is running from 2010 to 2019, with a migration starting in 2020 and lasting one year so that at the end of 2020 all users are connected to the NGOA, and the traditional access network can be switched off. It can be observed that the relative cost among the architectures is the same, independent of the area type. Of course, when possible, upgrading existing technological solutions has the lowest cost, as most of the existing ODN (though a lower split ratio may impose an ODN upgrade as well) and equipment (e.g., ONU) can be reused. As also foreseen by the component and system-cost overview, UDWDM-PON appears to be the most expensive solution, driven by the high OLT cost and less reliable components.

3) Migration Cost Assessment With Node Consolidation: Operators are considering node consolidation as an avenue to reduce costs associated with the number of central offices to be maintained. For the case of node consolidation, the average TCO per connected user has been evaluated for dense urban and rural areas as shown in Fig. 13. It can be observed that, in contrast to the first migration study in a nonconsolidation scenario, the relative costs among the architectures depend on the considered area. For dense urban areas, depending on the existing deployment, either an upgrade of XG-PON or a migration from AS-AON to AS-AON with WDM Backhaul shows the lowest cost due to the reuse of legacy network and infrastructure resources. Starting from G-PON, the less costly migration is toward hybrid WDM/TDM-PON.

In rural areas, starting from G-PON, migration toward hybrid WDM/TDM-PON has a similar cost to an (X)G-PON upgrade. Starting from AS-AON, migration toward WDM Backhaul with AON P2P remains a low-cost solution.

Furthermore, it can be observed that rural service areas have higher infrastructure costs than dense urban

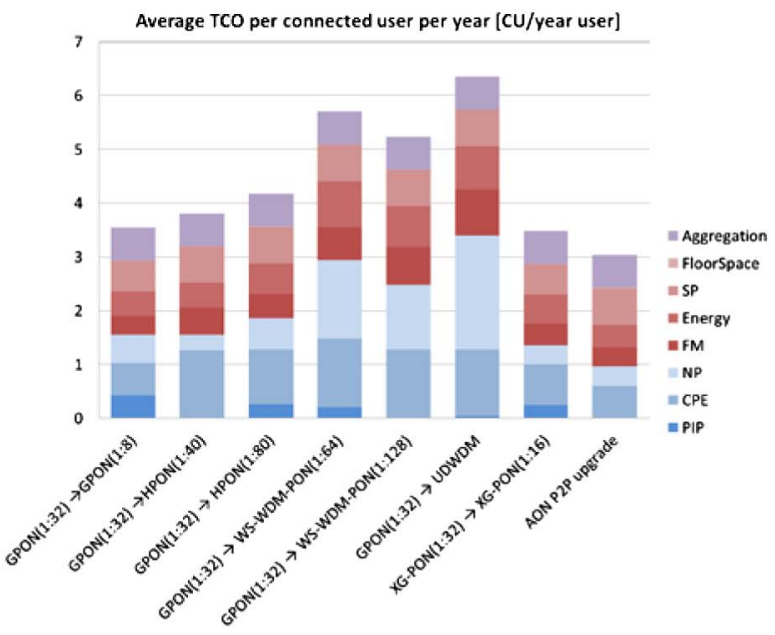

(a) Dense urban area

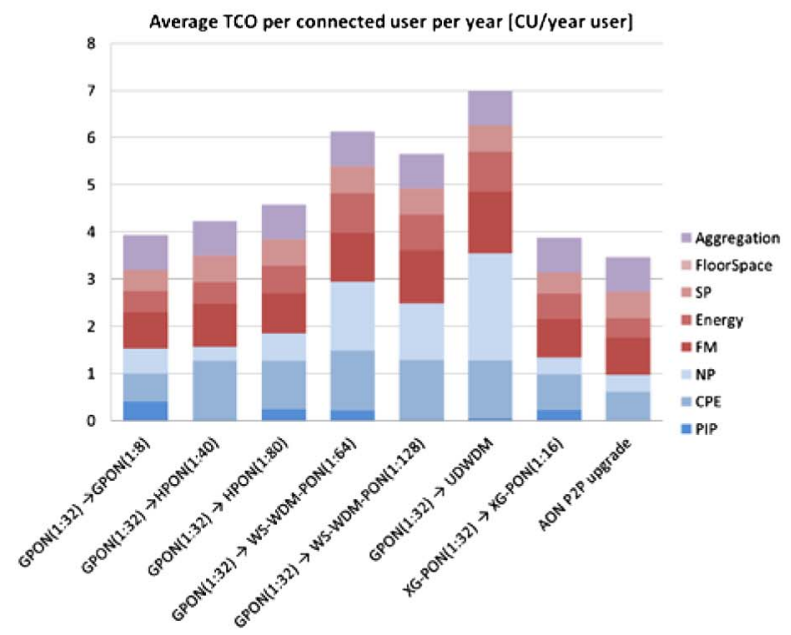

(b) Rural area

Fig. 12. Average nondiscounted TCO per connected user per year in today's deployment, e.g., 7500 nodes [no node consolidation (NNC) assumed]: (a) dense urban area and (b) rural area.

areas, but lower operational costs such as maintenance and power due to fewer users per service area. The case of upgrading from AON P2P in a NNC scenario to a nodeconsolidation scenario is not studied because of excessive costs: In an aggressive node-consolidated area, there is a higher number of users and longer ODN distances, which will lead to large fiber infrastructure costs to provide P2P connections between all users and their respective COs.

In order to better compare the techno-economic performance of no-node-consolidated and node-consolidated architectures, further studies included the aggregation network cost in the TCO calculation (an aggregation cost model and values have been provided in the project [20]). It has been observed that the savings on node consolidation depend on the architecture as well as the area. Node consolidation is strongly encouraged in rural areas, where the aggregation savings are significant. Note that additional savings associated with node consolidation, beyond 


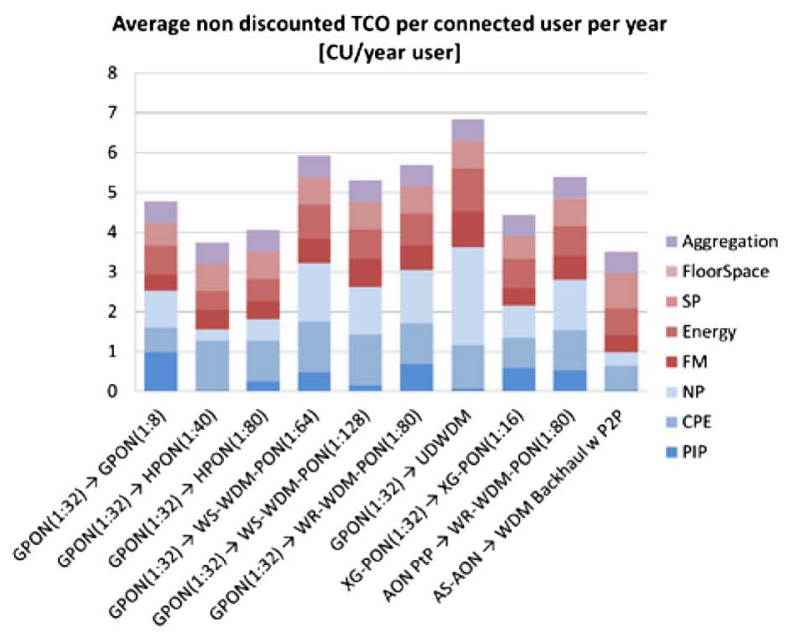

(a) Dense urban area

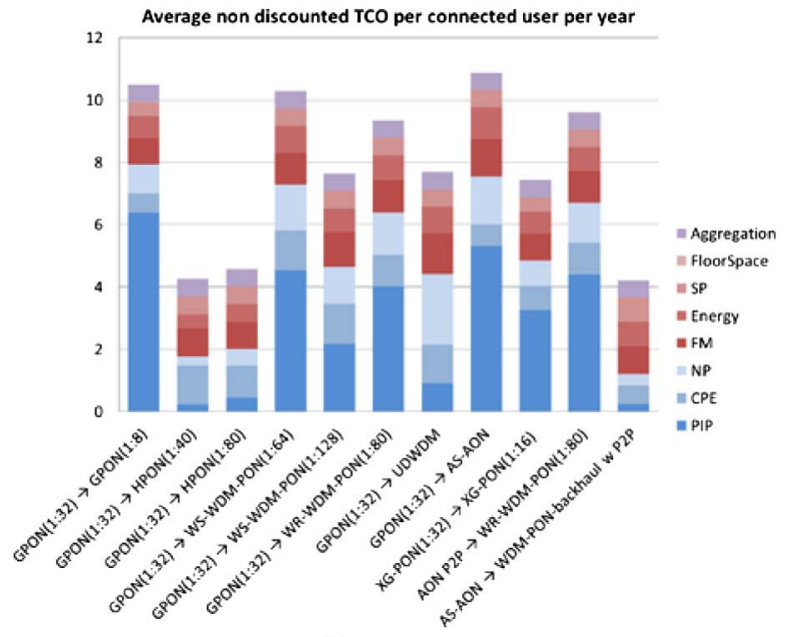

(b) Rural area

Fig. 13. Average nondiscounted TCO per connected user per year in the aggressive node-consolidation (ANC) scenario (1000 nodes): (a) dense urban area and (b) rural area.

what is presented here, are expected (e.g., property value of evacuated central offices).

4) Sensitivity Analysis: A sensitivity analysis was performed to render a more detailed view on the sensitivity of the results to assumptions on the main influencing aspects in the context of the network. It was discovered that a higher fan-out will, for all architectures, lead to a lower cost per home passed and to a lower overall cost. Cost reductions up to $30 \%$ and more are achievable by increasing the fan-out substantially (e.g., by a factor of 8). It should be noted that the higher fan-out cases might conflict with the consolidation possibilities because a higher fan-out will reduce the reach - and maximum dedicated bandwidthbecause more customers are sharing the same OLT port. Relaxing the OASE requirements-for instance, only in an initial phase-could reduce the upfront costs substantially. Regional differences could lead to a very different cost of deployment. Especially in European countries with

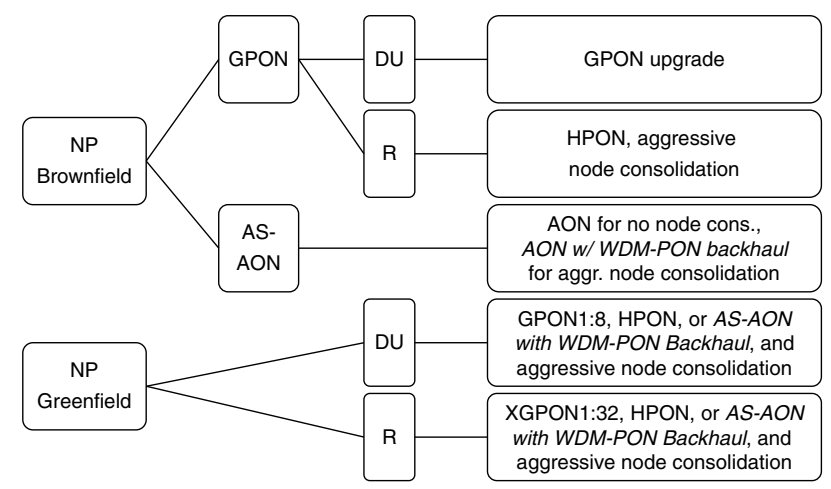

Fig. 14. Main NGOA migration paths.

lower average salaries, the costs could be much lower. Next to the salary, adoption is the most important impacting factor, and a higher adoption will lead to a lower cost per customer in the end.

Adoption has probably the highest impact of all factors and has been split into the initial adoption effect (e.g., by means of presubscriptions) and the steepness of the adoption curve. Increases in the initial adoption lead to the most substantial decrease in the cost per subscription year. The effect of having a faster adoption continues to be very important.

5) Concluding Remarks: The main findings regarding migration are summarized in Fig. 14 (assuming required sustainable bandwidth is less than $500 \mathrm{Mb} / \mathrm{s} / \mathrm{user}$ ). For further results from the techno-economic analysis, please refer to $[\underline{20-23]}$.

\section{Business Case Assessment of OASE Solutions}

As outlined in Subsection II.B, NGOA business roles are typically split into three conceptual levels: PIP, NP, and SP due to the technical and economic nature of the different parts of the network. In the following, the assessment of the business case for each role is presented summarily, with reference to specific studies for further detail.

1) Feasibility of the PIP Case: Based on an analysis of costs (model from Subsection IV.C) versus benefits (average monthly revenue of €10 per residential PIP connection, based on several realistic cases [22-28]), the business case for the PIP only proves viable in a dense urban area with aggressive adoption. The case can be improved, however, by a number of factors, which may help explain the fact that several deployments have been made in an economically sustainable way $[4,19]: 1)$ demand aggregation [29], i.e., presubscription of interested customers to the FTTH offer, leading to an assured substantial revenue stream for the PIP from the start of the project, therefore heavily reducing the investment risk; 2) duct reuse, drastically reducing costs; 3 ) fiber lease outside the broadband access, e.g., mobile backhauling, point-to-point connections for large businesses, banks and public institutions, and transport for operators, leading to additional revenues (which can be significant, as Stokab reported it can add up to 
$50 \%$ of its total revenue [30]); and 4) longer payback term [31], as also considered for other network infrastructures such as electricity or water, roads or railways. For example, in [32], it is calculated that for the considered reference scenario, the business case of the PIP in an urban area only becomes feasible if the payback term is increased from 20 to 40 years.

For some areas, even with the measures suggested above, greenfield fiber deployment may remain economically infeasible. In those cases, government funding might be the way out. Such intervention would be justified by positive externalities (indirect or cross-sectorial effects accruing outside the broadband access value chain), but are of significance for the economy and society at large $[33,34]$, which can be expected from a fiber deployment.

2) Providing an Open Infrastructure: Based on a qualitative analysis of the interactions between the different players in the value network (incumbent and alternative operators, municipalities, utilities, vendors, etc. [35]), fiber infrastructure deployed by a municipal infrastructure provider was shown to be the most promising. This can be explained both by the possible cost reduction (joint roll-out with other utilities and efficient coordination) and the relevant indirect effects (e.g., benefits for society that are typically directly valued by a municipality, such as increased attractiveness of the region).

A game theoretic analysis [36] allowed us to compare open and closed municipal infrastructures, from the viewpoint of all actors involved (municipal PIP, telcos, and other NPs) [37]. Under competition, it was shown that it is always more interesting to deploy the open-access network and that existing players will choose to migrate to the network. The extra revenues due to the increased uptake on the fiber network clearly offset the upfront and provisioning cost for the open network.

3) Feasibility of the NP Case: Our analysis showed that NPs can work cost-efficiently on top of an open infrastructure [4]. However, in-building deployment and customer premise equipment (CPE) are significant cost factors that need to be addressed (entirely accounted for by the NP, as we assume the PIP terminates in the building basement). If this dominant in-building cost could be shifted to another player (house owner or partial tenant),,-1 the business is positive for all scenarios (areas and adoption curves). Observing the case studies, we see that there is a limited set of NPs offering network connectivity in a certain area. Depending on the situation, either one NP wins the tender and offers exclusive connectivity for a predetermined period of time, or there is a free choice between different NPs offering connectivity to everyone. In any case, each end user would be connected to only one NP at any one point in time.

\footnotetext{
${ }^{1}$ Some examples exist of business cases in which property owners and tenants agree to a rent increase when in-building networks are installed (e.g., the infrastructure is viewed as an upgrade of the building in the same way as a new elevator or a facade renovation would be [36]).
}

4) Open Access From a Business Perspective: As indicated above, open access leads to important advantages: 1) Infrastructure sharing, which is the basis of open-access solutions, considerably reduces investment costs, and 2) open access enables competition between service providers, which is expected to lead to lower prices and more choice for end users.

However, the presence of different actors at different layers also induces some additional costs. We have modeled the open-access interfaces and calculated the costs in terms of extra equipment, as well as management, process, and business interfaces. The combination of these equipment-related costs, together with the management and process-related costs, form the production costs for the open offer, and the business-related costs are the so-called transaction costs [38]. Overall, additional costs induced by the cooperation between actors in an open-access scenario can amount to up to $20 \%$ of the yearly PIP revenues and will as such affect the profitability of this player [4].

From the perspective of transaction-cost reduction, there is a clear potential gain in promoting standardization, both at technical and business levels. There should be a coordinating rule set in place. This agreement should include all relevant technical processes (including, e.g., resource allocation), as well as business aspects/interfaces required for providing services to the customers. The rule set should be monitored and coordinated by an independent party and not by one of several NPs offering service in the same area. The coordinating party can be the PIP or another independent (public) entity.

5) Summary of Business Insights: Based on the three conceptual levels identified (PIP, NP, and SP), we have evaluated the business cases of the PIP and the NP. In several real deployments, the business case for the PIP is viable because of demand aggregation, duct reuse, the availability of additional revenues, and consideration of longer payback terms. The business case for the NP is positive if the dominant in-building cost can be shifted away. An open infrastructure will be an enabler for competition; however, the additional costs related to this opening are to be considered carefully. For further details, please refer to [39].

\section{Conclusions and Recommendations}

Based on the technical, architectural, and technoeconomic studies, as well as the assessment under business-related aspects, the following conclusions with respect to the considered NGOA system concepts can now be drawn.

\section{A. NGOA System Recommendation}

Due to a pure technical or even architectural assessment of the different proposed NGOA concepts, it is not possible to single out a main system contender for NGOA. Even introducing operational aspects like power consumption and floor space or analyzing the technical impact of system 
failures does not result in a clear favorite. The technology and architectural-driven analysis has clearly shown that almost every initial requirement can be fulfilled, if additional components like reach extenders, more fibers, or improved technical functionalities, such as superior receiver sensitivities or additional wavelength bands, can be embraced in the technical system's evolutions. Also, the studies of open access at the wavelength level reveal that this can be achieved with almost every WDM concept considered if additional components or fibers are introduced. However, all of these technological enhancements are associated with an additional system cost, as will be shown in this summary.

From a pure technology perspective, the maturity level of the different technologies and associated system concepts was also addressed to establish a technology roadmap. We conclude that this roadmap is somewhat in line with the current focus of the FSAN: a so-called TWDM approach, which is a hybrid WDM/TDM-PON approach with a limited number of wavelengths of between 4 to 10 channels.

Specifically, based on the final techno-economic analysis of the different NGOA concepts with the key assumption of a high guaranteed bandwidth during the busy hour of $300 \mathrm{Mb} / \mathrm{s}$, we conclude the following.

For a brownfield starting from a G-PON or AON $\mathrm{P} 2 \mathrm{P}$ deployment, in a no-node-consolidation scenario, G-PON/XG-PON or AON P2P is still the preferred lowcost solution, depending on the start scenario for the infrastructure:

- If one starts with a P2MP infrastructure, then G-PON or XG-PON will be the cost optimum.

- If one starts with a P2P infrastructure, then AON P2P gives the lowest costs; however, there is an additional initial investment for an AON P2P infrastructure in contrast to a P2MP.

- This holds independent of the area type, e.g., dense urban, urban, or rural.

- UDWDM is always the most cost-intense variant to migrate to, due to the high ONU cost.

- Hybrid WDM/TDM-PON is the lowest cost NGOA option using WDM-only as another scalability layer.

- WR- and WS-WDM-PON are in-between with respect to overall cost.

For a brownfield scenario starting from a G-PON or AON P2P deployment with a node-consolidation scenario goal, we can observe the following:

- AON-P2P has high cost in node consolidation and needs to be migrated to an AON-AS solution, where a first aggregation switch is at the cabinet level or in one of today's local exchanges.

- Migration toward WDM concepts using WDM as the access technology shows the highest cost in all considered areas.

- XG-PON shows the lowest cost in dense urban areas followed by a hybrid WDM/TDM-PON for migration from
G-PON due to reduced splitting for a high guaranteed data rate.

- In rural areas, due to the longer reach the active $\mathrm{RN}$ concepts (WDM backhaul) also enable a low-cost AONAS concept at similar cost like the migration of GPON toward a hybrid WDM/TDM-PON; XG-PON is not the preferred choice in long reach (rural areas) due to increased infrastructure costs due to low sharing compared to hybrid WDM/TDM-PON and WDMbackhaul concepts.

- Overall cost savings for hybrid WDM/TDM-PON and WDM backhaul are mainly due to cost savings in the aggregation network due to improved utilization of resources and lower cost per bit due to faster utilization of higher bit-rate interfaces offering lower cost per bit.

For a greenfield with G-PON or AON-P2P deployment, in a node-consolidation scenario

- AON P2P has very high initial infrastructure cost, therefore a P2MP infrastructure is the preferred choice,

- for moderate data rates $(<300 \mathrm{Mb} / \mathrm{s})$ pure G-PON or XGPON with reduced splitting is the preferred choice,

- hybrid WDM/TDM-PON concepts show the lowest infrastructure costs for a high guaranteed data rate.

From this cost study, it can be seen that, for sustained bit rates up to $500 \mathrm{Mb} / \mathrm{s}$, the NGOA concepts based on dedicated-wavelength customer access (e.g., UDWDM, WRor WS-WDM) are outperformed by the shared-wavelength approaches (such as G-PON, XG-PON, or AON AS), with WDM backhaul allowing for higher aggregation. For G-PON and XG-PON, the sharing takes place in the access infrastructure itself due to the TDM mechanism; in AON-AS, the sharing takes place in the switch located in the field. Therefore, in the context of the residential mass market, WDM from an economic point of view makes sense only as an additional overlay layer such as in the hybrid WDM/ TDM-PON concepts or WDM-backhaul concepts where WDM is purely used for increasing the scalability but not for addressing the residential customer. This conclusion is in good agreement with the focus of FSAN on hybrid WDM/TDM-PON concepts, specifically TWDM. In general, it has been shown that node consolidation enables cost savings that mainly occur in the aggregation network due to better equipment utilization.

From the investigated business concepts, on the other hand, increased operational complexity and additional requirements for coordination are unfavorable. Especially from an open-access perspective, WDM approaches with unbundling on wavelength level are more difficult in terms of business implementation compared to open access at the fiber level or bit-stream access.

\section{B. Strategic and Policy-Related Recommendations}

Based on our findings concerning the economic viability for the different actors involved in an NGOA deployment, 
we have formulated some recommendations for policy makers.

- From an open-access point of view, the preferred way of opening up a fiber-based access network remains either at the passive layer (fiber lease) or bit-stream open access as basically used today. Infrastructure-based competition (i.e., parallel fiber networks, one for each competitor) is very cost inefficient and is difficult to implement in a smooth and effective way at the end user's premises. Although in principle very interesting, open access at the wavelength layer (WDM) as an access technology for residential customers (e.g., a single wavelength per customer) results in significant additional system costs, further burdening the business case for any NP. More importantly, it is not obvious who would take care of the WDM splitters and wavelength management; currently, PIPs are reluctant to deal with that, while coordination between competing NPs introduces increased complexity and cost.

- The business case for the PIP remains challenging, even when using measures such as demand aggregation and duct reuse. However, significant extra revenue can be generated by offering a wholesale dark fiber lease to nontelecom actors. We observed in some studied cases that this can be up to $50 \%$ of total revenue, hence turning the business case from negative to viable. Moreover, a lot of indirect or cross-sectorial effects can be expected from a fiber deployment. This could be an additional stimulus for national, regional, or municipal governments to support investment. In this way, public support (in the form of state aid or other) may be desirable.

- In order for the above point to hold, the construction of passive infrastructure must be shared on an equal and nondiscriminatory basis. If the PIP is required to share the passive infrastructure, or the PIP is the only part of the value chain taken over by a single player, the deployed infrastructure should be technology-agnostic, meaning that fiber consolidation should take place at flexibility points where fibers can be connected and in which both active and passive equipment can be placed. This is important to maximize the potential wholesale customer base for a PIP. (Some NPs may run a PON, some an AON, and some hybrids thereof, so the passive infrastructure should be built so that all solutions are supported.) In consequence, higher costs have to be recouped as well, e.g., in the case of the cabinet flexibility point, calculations have shown that significant additional costs are incurred, and all involved parties need to share these in a fair manner.

- Public financial support should be focused on the PIP layer. Deployment of the physical infrastructure is mainly CAPEX-driven, in which case support may be granted in terms of long-term loans or over long depreciation periods, in order to increase the investment horizon.

- For the NP, in-house deployment and CPE are significant cost factors. Business models that allow the allocation of these costs to house- or home-owners should receive greater attention. However, public financial support to the NP is unadvisable in the long term.
In summary, this document gives an overview of the potential NGOA solutions examined in the project OASE, enabling optical access network technologies, architecture principles, and related economics, while taking CAPEX and OPEX into account. Key principles of the studies within OASE have included future network evolution toward node consolidation in the access network and understanding of the impact of new business models on network architectures.

\section{ACKNOWLEDGMENTS}

The research leading to these results has received funding from the European Union's Seventh Framework Programme under grant agreement no. 249025 (ICT-OASE). Parts of the present work were financed by the European Commission through the FP7 program under grant agreement no. 249025.

\section{REFERENCES}

[1] Analysis Mason, "Fibre capacity limitations in access networks," report for Ofcom, Jan. 2010.

[2] "Requirements for European next-generation optical access networks," OASE project deliverable D2.1, 2010.

[3] "Consolidated requirements for European next-generation optical access networks," OASE project deliverable D2.2, 2012.

[4] "Value network evaluation," OASE project deliverable D6.3, 2012.

[5] "Survey of next-generation optical access system concepts," OASE project deliverable D4.1, 2010.

[6] "Technical assessment, and comparison of next-generation optical access system concepts," OASE project deliverable D4.2, 2011.

[7] K. Grobe, M. Roppelt, A. Autenrieth, J.-P. Elbers, and M. Eiselt, "Cost and energy consumption analysis of advanced WDM-PONs," IEEE Commun. Mag., vol. 49, no. 2, pp. S25-S32, 2011.

[8] K. Grobe, M. Eiselt, J.-P. Elbers, and M. Roppelt, "Combined reach, client-count, power-consumption, and cost analysis of WDM-based next-generation PON," in European Conf. on Optical Communication (ECOC), Geneva, Switzerland, Sept. 2011, paper We.10.P1.113.

[9] R. Huelsermann, D. Breuer, K. Grobe, and J.-P. Elbers, "Combined OLT form-factor and power-consumption analysis for WDM-based next-generation PON," in 13th ITG-Fachtagung Photonische Netze, Leipzig, Germany, May 2012, pp. 132-136.

[10] L. Banchi, R. Corsini, M. Presi, and E. Ciaramella, "Investigation of the effects of chirped RZ signals in reducing the transmission impairments in R-SOA-based bidirectional PONs," J. Lightwave Technol., vol. 29, no. 8, p. 1165, Apr. 2011.

[11] M. Roppelt, M. H. Eiselt, K. Grobe, and J.-P. Elbers, "Tuning of an SG-Y branch laser for WDM-PON," in Optical Fiber Communication Conf., Los Angeles, CA, Mar. 2012.

[12] "Description, and assessment of the architecture options," OASE project deliverable D3.2, 2012.

[13] J. Chen, "Efficient resiliency mechanisms for next generation passive optical networks (invited)," in 9th Int. Conf. on Information, Communications, and Signal Processing (ICICS), Dec. 2013. 
[14] A. Dixit, J. Chen, M. Mahloo, B. Lannoo, D. Colle, and M. Pickavet, "Efficient protection schemes for hybrid WDM/TDM passive optical networks," in IEEE Int. Conf. on Communications (ICC), New Trends in Optical Networks Survivability, Ottawa, Ontario, Canada, June 2012.

[15] "Migration paths," OASE project deliverable D3.4, 2012.

[16] M. Mahloo, C. Mas Machuca, J. Chen, and L. Wosinska, "Protection cost evaluation of WDM-based next generation optical access networks," Opt. Switching Netw., vol. 10, pp. 89-99, Jan. 2013.

[17] “Co-operation models," OASE project deliverable D3.3, 2012.

[18] ftp://ftp.cordis.europa.eu/pub/ist/docs/ka4/mob_tonic.pdf.

[19] "Overview of methods, and tools," OASE project deliverable D5.1, Oct. 2010.

[20] "Process modelling, and first version of TCO evaluation tool," OASE project deliverable D5.2, Dec. 2011.

[21] "Techno-economic assessment studies," OASE project deliverable D5.3, Dec. 2012.

[22] C. Mas Machuca, S. Krauß, and K. Casier, "Fault management and service provisioning process model of next generation access networks," in Int. Conf. on Network and Service Management, Paris, France, Oct. 2011.

[23] C. Mas Machuca, K. Wang, S. Verbrugge, K. Casier, M. Kind, R. Hülsermann, and S. Krauß, "Cost-based assessment of NGOA architectures and its impact in the business model," in 11th Conf. on Telecommunication, Media and Internet Techno-Economics (CTTE), Athens, Greece, June 2012.

[24] Bundesnetzagentur, "Pressemitteillung: Bundesnetzagentur gibt endgültige Genehmigung der Entgelte für die 'letzte Meile' bekannt," June 17, 2011.

[25] "Besluit wholesale price cap 2009-2011 (WPC-IIa besluit)," OPTA/AM/2009/203507, Dec. 16, 2009.

[26] A. Broberg, "Stockholm IT-infrastructure," workshop presentation, Stokab, Stockholm, Feb. 2011.

[27] "Reggefibre, KPN Wholesale to adjust fibre tariffs," Telecompaper, Dec. 31, 2012 [Online]. Available: http://www.telecompaper .com/news/reggefiber-kpn-wholesale-to-adjust-fibre-tariffs--916449.

[28] Reggefibre, "Annex: Tarieven bij Overeenkomst inzakegebruik van passieve glasvezel-aansluitnetwerken," Version 2.4
[Online]. Available: http://www.eindelijkglasvezel.nl/tl_ files/documents/Generiek\%200DF\%20 contract/Annex $\% 20$ Tarieven\%20bij\%20ODF\%20overeenkomst\%20Reggefibre $\% 20 \mathrm{v} 2 \% 204 . p d f$.

[29] W. Burger, "The Reggefibre model. Key elements of Reggefibre's strategy in The Netherlands," 2012.

[30] A. Broberg, "Challenges for an open physical infrastructure provider," in European Conf. on Optical Communication (ECOC), Amsterdam, The Netherlands, Sept. 2012.

[31] C. Eijgenraam, C. Koopmans, P. Tang, and A. Verster, "Evaluatie van Infrastruurprojecten. Leidraad voor KostenBatenanalyse," CPB, Den Haag, The Netherlands, CPB Special Publication 22, 2000.

[32] M. Van der Wee, S. Verbrugge, M. Tahon, D. Colle, and M. Pickavet, "Evaluation of the techno-economic viability of passive fiber access infrastructure deployment in Europe," J. Opt. Commun. Netw., vol. 6, pp. 238-249, 2014.

[33] M. Forzati, C. Mattsson, K. Wang, and C. P. Larsen, "The uncaptured values of FTTH (invited)," in 13th Int. Conf. on Transparent Optical Networks (ICTON), Stockholm, Sweden, June 2011.

[34] M. Forzati, "Socio-economic effects of FTTH/FTTx in Sweden (invited)," in 14th Int. Conf. on Transparent Optical Networks (ICTON), Warwick, UK, July 2-7, 2012.

[35] J. Arcade, M. Godet, F. Meunier, and F. Roubelat, "Structural Analysis With the MICMAC Method \& Actors' Strategy With MACTOR Method," American Council for the United Nations University: Millenium Project, Washington DC, 1999.

[36] B. L. Slantchev, "Game Theory: Dominance, Nash Equilibrium, Symmetry," 2008.

[37] M. Tahon, S. Verbrugge, D. Colle, M. Pickavet, P. Wright, and A. Lord, "Valuing flexibility in the migration to flexgrid networks," in Optical Fiber Communication Conf. and the Nat. Fiber Optic Engineers Conf. (OFC/NFOEC), Anaheim, CA, USA, Mar. 2013.

[38] O. Williamson, "The economics of organization: the transaction cost approach," Am. J. Sociol., vol. 87, no. 3, pp. 548-577 1981.

[39] "Market demands, and revenues," OASE project deliverable D6.2, 2011. 